\title{
Partitioning of Airway and Parenchymal Mechanics in Unsedated Newborn Infants
}

\author{
J. JANE PILLOW, JANET STOCKS, PETER D. SLY, AND ZOLTÁN HANTOS
}

Portex Unit [J.J.P., J.S.], Respiratory Physiology, Institute of Child Health, London, WC1N 1EH, UK; Neonatal Unit [J.J.P.], University College London Hospital, London, WC1E 6DH, UK; Institute for Child Health Research [J.J.P., P.D.S., Z.H.], School of Women's and Infants' Health [J.J.P.], University of Western Australia, Perth, 6008 Australia; Department of Medical Informatics and Engineering [Z.H.], University of Szeged, Szeged, H-6720, Hungary

\begin{tabular}{|c|c|}
\hline \multicolumn{2}{|c|}{ ABSTRACT } \\
\hline $\begin{array}{l}\text { The recent trend toward development of noninvasive methods } \\
\text { that can accurately evaluate the lung periphery has particular } \\
\text { relevance for the predominantly parenchymal nature of neonatal } \\
\text { respiratory disease. Concerns regarding the safety of sedating } \\
\text { newborn (especially preterm) infants have also stimulated a drive } \\
\text { toward measurements obtained during natural sleep. This study } \\
\text { aimed to adapt existing methodology for the low-frequency } \\
\text { forced oscillation technique to obtain partitioned measurements } \\
\text { of airway and parenchymal mechanics during unsedated, quiet } \\
\text { sleep in newborn infants without a history of previous respiratory } \\
\text { disease. A face mask was positioned over the infant's mouth and } \\
\text { nose and a brief ( } 4-5 \text { s) breathing pause was induced by evoking } \\
\text { the Hering-Breuer reflex via end-inspiratory occlusion at raised } \\
\text { lung volume (airway opening occluded at } 2 \mathrm{kPa} \text { ). Airway open- } \\
\text { ing pressure and flow were measured while a pseudorandom } \\
\text { noise ( } 2-14 \mathrm{~Hz} \text { ) was applied to the airway. Acceptable pulmo- } \\
\text { nary impedance data were collected in } 11 \text { of the } 12 \text { infants } \\
\text { studied ( } 34.1-42.6 \text { wk postmenstrual age, } 1.9-3.9 \text { kg body } \\
\text { weight) on } 17 \text { (total of 20) occasions. Airway parameters (resis- }\end{array}$ & $\begin{array}{l}\text { tance and inertance) and respiratory tissue parameters were } \\
\text { calculated from the resultant impedance spectra. Tissue resis- } \\
\text { tance and tissue elastance decreased with increasing body length } \\
\text { albeit at different rates such that hysteresivity (tissue resistance/ } \\
\text { tissue elastance) also decreased. There was a trend toward re- } \\
\text { duction in airway resistance with increasing length. Measure- } \\
\text { ments of lung function are feasible in the unsedated newborn } \\
\text { infant using low-frequency forced oscillations and confirm the } \\
\text { important contribution of tissue resistance to lung mechanics in } \\
\text { the developing lung. (Pediatr Res } \mathbf{5 8 : ~ 1 2 1 0 - 1 2 1 5 , ~ 2 0 0 5 ) ~} \\
\text { Abbreviations } \\
\text { } \text {, hysteresivity (G/H) } \\
\text { G, coefficient of tissue resistance (tissue damping) } \\
\text { H, coefficient of tissue elastance (1/compliance) } \\
\text { LFOT, low-frequency forced oscillation technique } \\
\mathbf{R}_{\mathbf{a w}} \text {, airway (Newtonian) resistance } \\
\mathbf{Z}_{\mathbf{r s}} \text {, respiratory system impedance }\end{array}$ \\
\hline
\end{tabular}

Parenchymal disease processes such as surfactant deficiency, pulmonary interstitial emphysema, and pulmonary hemorrhage dominate the spectrum of neonatal respiratory disease. Chronic lung disease in the extremely preterm infant may also have a significant parenchymal component due to disrupted alveolar development $(1,2)$ and deranged pulmonary vasculature (3). There is a real need for information about the

Received January 24, 2005; accepted June 1, 2005

Correspondence: J. Jane Pillow, FRACP, Ph.D., Neonatal Clinical Care Unit, King Edward Memorial Hospital, 374 Bagot Rd., Subiaco, 6008, Perth, Western Australia, Australia; e-mail: janep@ichr.uwa.edu.au

This research was supported by a Neil Hamilton Fairley NHMRC Postdoctoral Fellowship (J.J.P.), SPARKS (Sport Aiding Medical Research in KidS), a British CouncilHungarian Government Collaborative Research Grant, the Hungarian Medical Research Council Grant (519/2003), and Portex Ltd (J.S.). Research at the Institute of Child Health and Great Ormond Street Hospital for Children NHS Trust benefits from R\&D funding received from the NHS Executive.

DOI: 10.1203/01.pdr.0000185273.86320.13 functional consequences of disease and response to therapy in late gestation and early postnatal life as well as later growth and development of the respiratory system. Such assessments are not only notoriously difficult in preterm infants due to short epochs of natural, quiet sleep, frequent feeds, and rapid and irregular breathing patterns, but have provided limited information about the separate influences of the different disease processes on the airways and the lung tissue. The traditional and commonly used techniques for bedside measurement of infant lung mechanics (4) are inappropriate or of low specificity for the partitioning of global respiratory or pulmonary mechanics, stimulating a recent trend toward development of noninvasive methods that can accurately evaluate the lung periphery $(5,6)$.

One particularly promising approach is the FOT, initially proposed by DuBois et al. (7) in 1956 to measure the impedance of the total respiratory system $\left(Z_{r s}\right)$ and recently reviewed 
in detail (8). In this technique, a loudspeaker is used to deliver a small-amplitude pressure wave form at varying frequencies, and these pressures are related to resultant changes in flow at each of the component frequencies in the signal. The concept of impedance describes the complex resistive nature of a system against external perturbations. When the frequency of the external forcing varies, the impedance becomes a function of frequency and can be further characterized by elastic resistance (elastance or compliance) and dissipative resistance, both exhibiting characteristic frequency dependences. Impedance consists of resistive (when changes in pressure and flow are in phase) and reactive (when changes in pressure and flow are out of phase, i.e. changes in pressure are in phase with changes in lung volume) components. The reactive relationships are determined by the elastance of the tissues and the inertance of the accelerated air in the airways. Modification of the FOT to encompass low oscillation frequencies reveals the characteristically different and thereby separable mechanical properties of the airways and the respiratory tissues (9). At low frequencies, the resistance and reactance decrease nearly hyperbolically with increasing frequency. At higher frequencies, the tissue properties become less important and the largely frequencyindependent airway properties of resistance and inertance dominate (10). Variables representing the mechanical properties of the airways (resistance and inertance) and the tissues (resistance or "damping" and the elastance) can be obtained by fitting a model to the impedance spectra (9).

The major limitation to the LFOT is the requirement of apnea during the external oscillations, because the smallamplitude oscillatory signal does not contain sufficient power to suppress the influence of the higher harmonics of spontaneous breathing up to a frequency of several hertz. This difficulty has been overcome recently in sedated infants aged from $1 \mathrm{mo}$ to 2 yrs by employing the Hering-Breuer inflation reflex and hyperventilation to induce a short apneic interval (11), during which low-frequency $(0.5-20 \mathrm{~Hz}) \mathrm{Z}_{\mathrm{rs}}(11-17)$ is measured. The use of sedation is generally contraindicated for lung function tests in healthy, spontaneously breathing infants $<44$ wk postconceptional age (18). This is particularly so in preterm infants as they are at increased risk of respiratory depression, upper airway obstruction, and aspiration following vomiting, each of which are known side-effects of chloral hydrate, the most commonly used sedative agent for infant lung function tests. To achieve clinical and parental acceptance of LFOT measurements in newborn infants, studies would need to be performed in the absence of sedation. A second barrier to cotside application of the LFOT in newborn infants has been the bulky, laboratory-based nature of preexisting equipment.

The main aim of this study was to modify existing methodology and equipment for measuring $\mathrm{Z}_{\mathrm{rs}}$ using the LFOT, to facilitate portable cotside studies in unsedated newborn infants. A secondary goal was to establish the relative contributions of the airways and lung parenchyma to $\mathrm{Z}_{\mathrm{rs}}$ and its relationship to body size during the early phase of alveolarization, in a cross-sectional study of predominantly preterm newborn infants without a history of significant previous respiratory illness.

\section{METHODS}

Study population, ethics, and background data. Spontaneously breathing nonventilated newborn infants were recruited from the Neonatal Unit at University College London Hospital for forced oscillatory measurement if written informed parental consent was obtained, and they had no congenital abnormalities or significant previous history of respiratory illness. Body weight and crown-heel length were measured as described previously (18). The Joint UCL/UCLH Committees on the Ethics of Human Research approved the studies.

Measurement of oscillatory mechanics. The LFOT measurements were made during quiet sleep (18) at least $30 \mathrm{~min}$ after a feed. Oxygen saturation and heart rate were continuously monitored throughout the study (Nellcor 290, Nellcor, Pleasanton, CA). The measurement set-up (Fig. 1) was modified from that used by Sly and colleagues (11) by including an infant resuscitator (Neopuff, Fisher-Paykel Healthcare Ltd., Auckland, NZ) and a manual shutter valve. A breathing pause was induced using the Hering-Breuer reflex: lungs were inflated (over approximately $1 \mathrm{~s}$ ) to $2 \mathrm{kPa}$ for three consecutive breaths by manually occluding the expiratory port of the infant resuscitator delivering compressed air at $12 \mathrm{~L} / \mathrm{min}$. The manual shutter was activated at endinspiration on the third breath to effect an airway occlusion for a period of no more than $5 \mathrm{~s}$. A pseudorandom signal comprising low-amplitude $(0.1-0.2$ $\mathrm{kPa}$ ) pressure fluctuations ranging between 2 and $14 \mathrm{~Hz}$ was generated by a loudspeaker-in-box and delivered to the airway opening via a screen pneumotachograph and a disposable hydrostatic bacterial filter (Hygrobaby, Nellcor). A silicone face mask of size 0/1 (Laerdal Medical Ltd., Orpington, Kent, UK) was placed firmly over the subject's mouth and nose to achieve a leak-free seal. Differential pressure transducers (model 33NA002D, IC Sensors, Milpitas, $\mathrm{CA}$ ) were used to measure the transrespiratory pressure at the airway opening and oscillatory flow across the pneumotachograph. An interval of $>1 \mathrm{~min}$ elapsed between consecutive measurements and an average of three technically

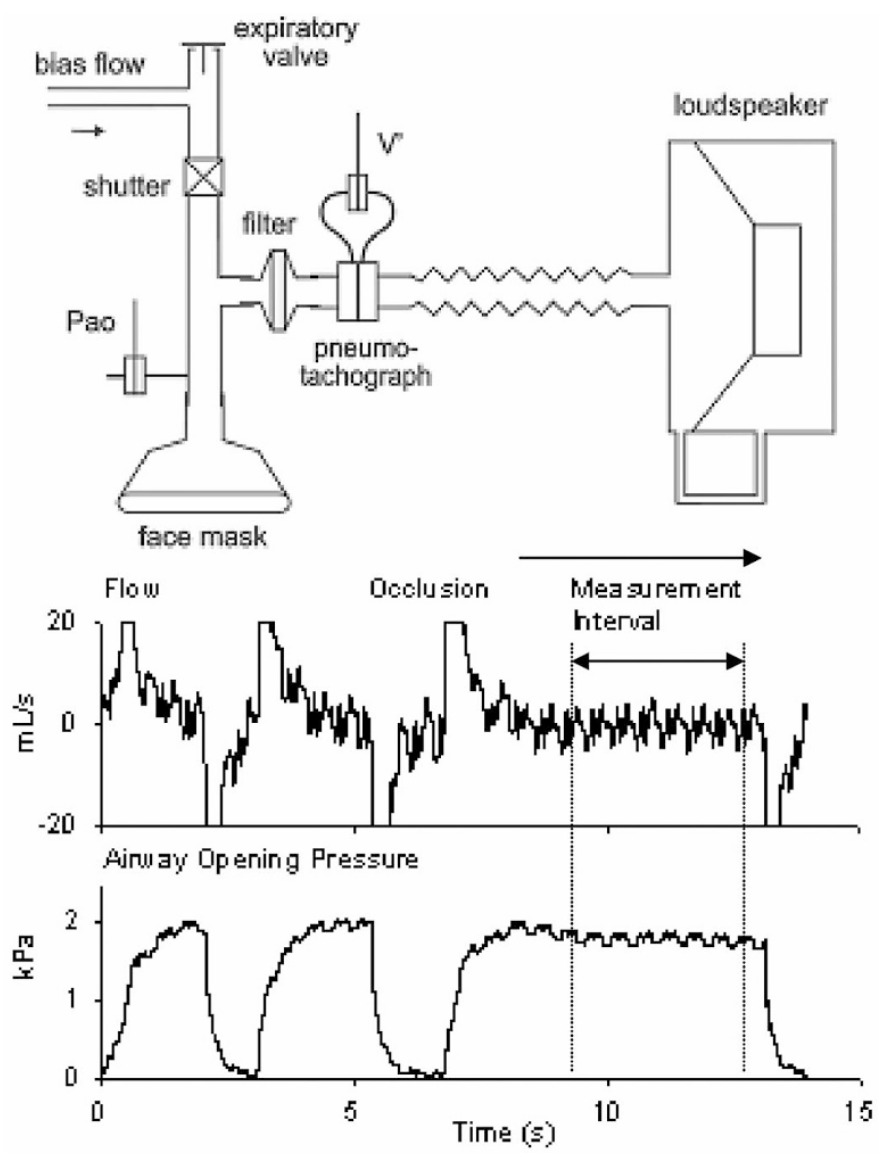

Figure 1. Measurement setup and protocol for the low-frequency oscillatory estimation of respiratory mechanics. (A) Equipment for measurements of low-frequency forced oscillatory mechanics in newborn infants. (B) Sample flow and pressure trace showing three manual inflations to $2 \mathrm{kPa}$ with occlusion of the airway opening on the third inflation and period of interval of stable pressure and flow used for computation of oscillatory mechanics. 
satisfactory and consistent measurements were obtained on each test occasion. Whenever a breathing effort or movement was observed during the oscillations, the face mask was removed; recordings of $>2 \mathrm{~s}$ duration and stable mean airway opening pressure levels indicating leak-free seal around the face mask were retained for further processing.

Data analysis. The airway opening pressure and flow signals were low-pass filtered at $50 \mathrm{~Hz}$ and digitized at $256 \mathrm{~Hz}$ by an analog-to-digital board of a personal computer. Data were considered technically acceptable if there was no evidence of leak, breathing, or movement artifact during the recording and the coherence of $Z_{\mathrm{rs}}$ at each frequency was $>0.95$ (8). The $Z_{\mathrm{rs}}$ data computed from the successive recordings in each subject were ensemble-averaged and corrected for the impedance of the equipment deadspace and face mask, as described previously in detail (11) and then fitted by a model consisting of an airway resistance $\left(\mathrm{R}_{\mathrm{aw}}\right)$, airway inertance, and coefficients of tissue resistance (G) and tissue elastance (H) (9). All frequencies were included in the model fitting except those coinciding with and corrupted by the heart rate and its harmonics. Tissue hysteresivity $(\eta)$ was calculated as $\eta=\mathrm{G} / \mathrm{H}$ (19). Spearman's correlation coefficients between lung mechanics and subject age and body size were determined using a statistical software package (SPSS v10.0.5, SPSS Inc., Chicago, IL).

\section{RESULTS}

Technically satisfactory measurements of $\mathrm{Z}_{\mathrm{rs}}$ were obtained in 11 out of 12 infants on 17 (total 20) test occasions. The characteristics of the study group are summarized in Table 1. All but two of the infants were born prematurely. The median time from commencement of LFOT tests to completion of tests was $47 \mathrm{~min}$ (range, 10-146 min). Three infants woke during the test and required resettling before recommencing and completing measurements. Approximately $50 \%$ of measurements within a test period were considered unsatisfactory and not retained for analysis. The main reason for unsatisfactory measurements was the occurrence of leak, subsequently found to be due to an intermittent fault with the occlusion valve. No adverse events were noted during or following the measurements.

Sample averaged $\mathrm{Z}_{\mathrm{rs}}$ spectra obtained in three infants of differing sizes are shown in Figure 2. A greater frequency

Table 1. Infant characteristics

\begin{tabular}{ccccccc}
\hline Infant & Sex & $\begin{array}{c}\text { GA } \\
\text { (wk PMA) }\end{array}$ & $\begin{array}{c}\text { Test age } \\
(\text { wk PMA) }\end{array}$ & $\begin{array}{c}\text { Wt } \\
(\mathrm{kg})\end{array}$ & $\begin{array}{c}\text { Length } \\
(\mathrm{cm})\end{array}$ & $\begin{array}{c}\mathrm{RR} \\
\text { (breaths/min) }\end{array}$ \\
\hline 1 & $\mathrm{M}$ & 35.4 & 37.1 & 1.91 & 45.5 & 36 \\
2 & $\mathrm{~F}$ & 33.4 & 36.7 & 2.36 & 46.0 & 52 \\
& & & $37.3^{*}$ & 2.46 & 46.1 & 50 \\
3 & $\mathrm{~F}$ & 35.3 & 37.4 & 2.32 & 46.9 & 50 \\
4 & $\mathrm{~F}$ & 32.1 & 34.6 & 1.68 & 39.5 & 68 \\
& & & $35.0^{*}$ & 1.77 & 40.2 & 76 \\
& & & 40.0 & 2.57 & 45.0 & 44 \\
5 & $\mathrm{M}$ & 33.0 & 36.6 & 1.78 & 41.8 & 40 \\
& & & 42.0 & 3.12 & 46.9 & 50 \\
6 & $\mathrm{M}$ & 34.0 & 36.0 & 2.40 & 47.1 & 36 \\
7 & $\mathrm{~F}$ & 33.7 & 37.3 & 2.97 & 49.5 & 42 \\
& & & 42.3 & 4.66 & 53.9 & 38 \\
8 & $\mathrm{~F}$ & 40.4 & 42.6 & 3.88 & 50.9 & 42 \\
9 & $\mathrm{~F}$ & 35.7 & 37.3 & 1.65 & 40.0 & 56 \\
& & & 43.3 & 3.30 & 47.9 & 50 \\
10 & M & 35.7 & 37.3 & 2.10 & 42.7 & 46 \\
& & & 43.3 & 4.3 & 49.5 & 40 \\
11 & M & 31.0 & 34.1 & 1.93 & 42.6 & 55 \\
& & & 38.9 & 3.15 & 46.3 & 52 \\
12 & F & 37.9 & $41.0^{*}$ & 3.37 & 45.12 & 32 \\
Mean (SD) & $34.1(2.3)$ & $38.6(3.0)$ & $2.7(0.9)$ & $46.0(3.8)$ & $46.9(8.5)$ \\
\hline
\end{tabular}

GA, gestational age; PMA, postmenstrual age; RR, respiratory rate; $\mathrm{Wt}$, weight.

* Unsuccessful measurement.

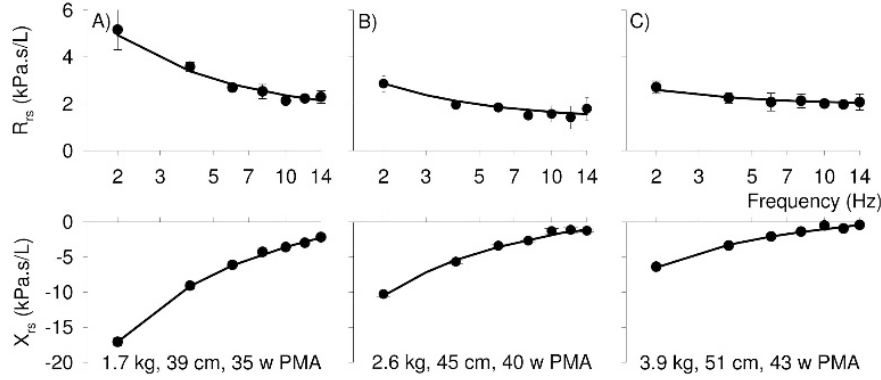

Figure 2. Impedance spectra-impedance data for two newborn infants [one preterm $(A, B)$ and one term $(C)]$ encompassing the spectrum of infant size and maturity in the study group and demonstrating the alteration in impedance spectra occurring with postnatal maturation $(A, B)$. (A) Infant \#4, occasion 1; (B) Infant \#4, occasion 3; (C) Infant \#8 (see Table 1). Solid lines indicate the model fitting. $\mathrm{R}_{\mathrm{rs}}$, respiratory resistance; $\mathrm{X}_{\mathrm{rs}}$, respiratory reactance; PMA, postmenstrual age. Symbols and bars: Mean and \pm SD values from technically acceptable measurements in the same infant.

dependence of respiratory resistance (rate of decrease in respiratory resistance with increasing frequency) in these small infants compared with that in older infant populations enabled the use of oscillatory signals of a higher fundamental frequency and consequent shorter durations of the oscillatory measurements than those used previously $(13,14)$. Respiratory reactance remained negative in the measured frequency range, reflecting the dominance of the elastic properties of the respiratory system and the small influence of the inertive properties. Consequently, the values of inertance were weakly estimated by the model fitting and they are not reported.

The model parameters obtained in each infant were most closely associated with length rather than weight (see Table 2) and are plotted against length in Figure 3. The average fitting error (root-mean-square error between the modeled and measured impedance data, normalized by the impedance magnitude) was $4.4 \% \pm 1.2 \%$. With increasing body size, there was a strong negative correlation between length and the coefficients of tissue resistance $(\mathrm{G})(p<0.0001)$ and tissue elastance $(\mathrm{H})(p=0.001)$, and a weak trend toward association between length and $\mathrm{R}_{\mathrm{aw}}$ was also apparent $(p=0.15)$. The difference between the slope of the $\mathrm{G}$ and $\mathrm{H}$ versus. length relationships was reflected in a decrease in tissue hysteresivity $(\eta=\mathrm{G} / \mathrm{H})$ with increasing length $(p=0.01)$.

\section{DISCUSSION}

We present the first report of successful partitioned measurements of airway and tissue mechanics achieved using LFOT at raised lung volume in a group of unsedated and

Table 2. Nonparametric correlations between respiratory mechanics and infant characteristics

\begin{tabular}{lccccl}
\hline & $\begin{array}{c}\text { Gestation } \\
\text { (wk PMA) }\end{array}$ & $\begin{array}{c}\text { Male } \\
\text { sex }\end{array}$ & $\begin{array}{c}\text { Test age } \\
\text { (wk PMA) }\end{array}$ & Weight & Length \\
\hline Raw & 0.23 & $-0.50^{*}$ & 0.09 & -0.17 & -0.29 \\
G & -0.19 & 0.21 & $-0.50^{*}$ & $-0.76^{* *}$ & $-0.80^{* *}$ \\
H & -0.37 & 0.28 & -0.40 & $-0.58^{*}$ & $-0.68^{* *}$ \\
$\eta$ & 0.06 & -0.14 & $-0.50^{*}$ & $-0.72^{* *}$ & $-0.65^{*}$ \\
\hline
\end{tabular}

Values indicate Spearman's rho.

$* p<0.05$; ** $p<0.01$. 

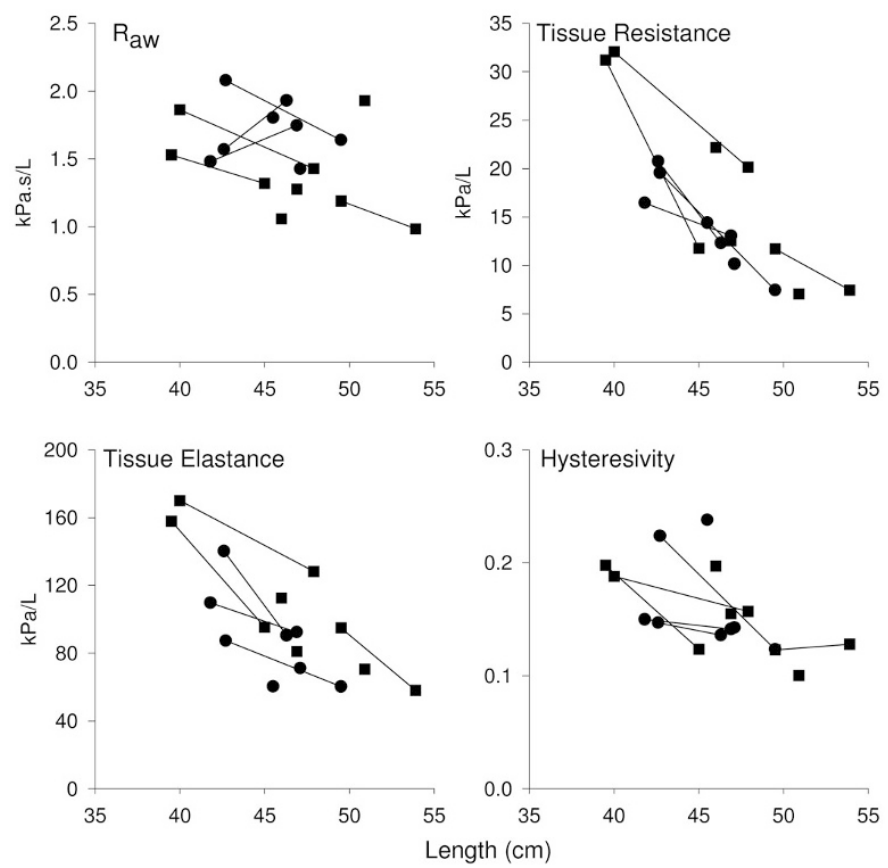

Figure 3. Changes in LFOT parameters with increasing length. Solid lines connect serial measurements obtained in six of the infants studied. Circle, male; square, female; $\eta$ (eta), hysteresivity calculated as $\mathrm{G} / \mathrm{H}$ and percentage model fitting error.

predominantly preterm newborn infants during quiet sleep. The measurements reveal the dominant contribution of the tissues to both the resistive properties and to total impedance of the human respiratory system during late gestation, reinforcing earlier observations in the preterm lamb (20-22).

Methodological considerations. The main modifications incorporated into the equipment setup to facilitate portability and application to the newborn population were the use of: 1) a neonatal resuscitator (Neopuff, Fisher \& Paykel); 2) a manual shutter occlusion valve; and 3 ) the use of a modified forcing signal. Previously, signals used during low-frequency forced oscillations in infants aged 1 mo to $2 \mathrm{y}$ of age have included frequency components spanning the range from $0.5 \mathrm{~Hz}$ (fundamental frequency) to $20 \mathrm{~Hz}(11,13,14,16)$. The inclusion of frequencies below $2 \mathrm{~Hz}$ has been considered important to allow for the manifestation of the negative frequency dependence of $\mathrm{R}_{\mathrm{rs}}$ attributed to the mechanical properties of the tissues, and hence enable the reliable estimation of both airway and tissue resistance from the $\mathrm{Z}_{\mathrm{rs}}$ data. The characteristic negative frequency dependence of $\mathrm{R}_{\mathrm{rs}}$, which is shifted to higher frequencies in the newborn and immature lung (see Fig. 2), allowed the use of oscillatory signals with a higher fundamental frequency, facilitating collection of valid measurements during endinspiratory pauses lasting as short as $1.5 \mathrm{~s}$ (three oscillation periods) in duration. The ability to obtain technically satisfactory recordings during relatively short apneic intervals has several potential benefits: Although the Hering-Breuer inflation reflex is relatively strong in young infants (particularly those born preterm) (23), the higher respiratory rate and shorter expiratory time in such subjects means that the absolute duration of the apneic pause may be limited. In addition, it should facilitate future attempts to undertake physiologically relevant
LFOT measurements at FRC, which have been precluded in older infants by the brevity of the expiratory pause after airway occlusions at low lung volumes (16). Likewise, measurements of tissue mechanics at the mean distending pressure during high-frequency oscillatory ventilation in the preterm lamb have identified the point at which optimal lung volume is achieved in the paralyzed preterm lamb (22). As respiratory drive is suppressed during high-frequency oscillatory ventilation $(24,25)$, use of the LFOT coupled with brief airway occlusions in unparalyzed infants may provide the physician with clinically informative lung mechanics at the prevailing lung volume without the need to invoke the Hering-Breuer reflex by further raised volume maneuvers.

Our estimates for $\mathrm{R}_{\mathrm{aw}}$ were obtained from the total respiratory impedance and thus include all Newtonian (frequencyindependent) components from the airways and tissues including the Newtonian resistance of the chest wall, although the contribution of the chest wall to the high frequency (Newtonian) respiratory resistance is relatively small (26). Likewise, $\mathrm{H}$ reflects the sum of the pulmonary and chest wall elastic resistances. We argue that, because the chest wall represents a relatively compliant compartment in the infant (16), H (and G) would be dominated by the lung parenchyma and the contribution of the chest wall to Newtonian resistance would be even less significant. These assumptions on the pulmonary/chest wall partitioning require confirmation, especially in view of the different developmental phases in this age group. The necessary inclusion of esophageal pressure transducers to obtain chest wall impedance would increase the invasiveness of the investigation, and was thus not an objective of the current study.

Use of an airway opening input impedance technique potentially allows extrathoracic airway wall shunting to impact on the measured impedance (27). A previous study showed that extrathoracic airway wall structures have negligible impact on the measurement of the tissue properties in infants using the LFOT, after correction for the parallel shunt imposed by the equipment deadspace and face mask, and when firm support of the cheeks and jaw are maintained throughout the measurement (13). This can be explained by the relative rigidity of the nasal passages compared with the oral structures, and also by the similar frequency dependencies of $\mathrm{Z}_{\mathrm{rs}}$ and the upper airway wall impedance (10) in the low-frequency region. On the other hand, inclusion of the nasal passage in the impedance measurement exerts a more marked effect on airway resistance and inertance (13), although to a lesser extent than observed during forced oscillations at higher frequencies (27). The inclusion of nasal impedance in the estimation of $Z_{\mathrm{rs}}$ should have the effect of decreasing resonance frequency of the measured system (13). The lack of an observed resonance frequency in our impedance spectra compared with previous studies $(13,27)$ is likely to be due to the relatively immature population of our babies, and the absence of a tracheal tube (28).

Physiologic significance. The major message from these initial measurements is that the parameters reflecting tissue mechanics (tissue resistance and tissue elastance) decrease markedly in the developing human lung during late gestation and early postnatal life. Our current findings agree with observations from our earlier investigation that differences in respi- 
ratory mechanics related to fetal lung maturation, as assessed in preterm lambs of differing gestations and/or exposure to maternal corticosteroid administration, are also most evident in the parameters of tissue resistance and tissue elastance (21). The observations are consistent with rapid development of the lung tissue occurring during the early neonatal period. The extent to which these changes in $\mathrm{Z}_{\mathrm{rs}}$ are attributable to the shape and composition of the chest wall and the lung is not estimable without separately estimating chest wall and parenchymal mechanics (17).

Animal models have shown that the collagen content and stiffness of lung tissue increases with maturation and we would expect, therefore, to find an increase in both $\mathrm{G}$ and $\mathrm{H}$ if the lung size did not change with maturation. In contrast, the observed decrease in $\mathrm{G}$ and $\mathrm{H}$ suggest that our findings are most likely to be explained by an increase in lung volume and surface area. The apparent negative correlation between tissue hysteresivity and length within this small and young infant cohort suggests that there may also be a change in the balance between viscous and elastic mechanical forces within the tissues during this alveolarization period of human lung development. Furthermore, hysteresivity would be expected to decrease with increasing lung volume, as collagen increasingly dominates lung mechanics with increasing lung volume $(16,29,30)$. For the same reason, a reduction in hysteresivity with increasing body length is consistent with a maturational increase in the microscopic collagen content of the tissue. An elevated value for hysteresivity has also been observed in the presence of inhomogeneities. Any decrease in hysteresivity with increasing body length may reflect improved homogeneity of the respiratory system. Given that the current measurements were obtained at elevated lung volume, we would expect any inhomogeneities present at FRC to be significantly reduced and hence to have minimal influence on the reported $\mathrm{Z}_{\mathrm{rs}}$.

The effect of measuring $Z_{\mathrm{rs}}$ at elevated lung volume on partitioning of airway and tissue mechanics is an important consideration. Airway resistance decreases while tissue resistance increases with increasing lung volume and hence the partitioning of $\mathrm{R}_{\mathrm{rs}}$ to airway and tissue components may be more advantageous at a higher lung volume (29). We demonstrated similar marked partitioning of airway and tissue compartments in the preterm lamb when measurements were made at a positive end-expiratory pressure of $0.3 \mathrm{kPa}(21)$, suggesting that similar findings are obtained in the low volume lung. Likewise, earlier observations demonstrating dominant effect of tissue resistance in the surfactant deficient preterm lamb lung, which is not evident after surfactant replacement (22), suggest that our findings in preterm infants remain of significant interest and are worthy of further investigation at different lung volumes. Measurements made at different transrespiratory pressures would also be important to account for the changing relative lung volumes during maturation.

Although the relatively small absolute change in airway parameters with increasing body size may be surprising, this study was conducted within a relatively heterogeneous group of infants with a limited range of postnatal age and variation in length. No similar comparative data for $\mathrm{R}_{\mathrm{aw}}$ exist for the preterm newborn infant at raised lung volume, however, the resistances observed in this study are of similar magnitude to previously published relationships between resistance and length using the LFOT technique in older infants (14). The discrepancy between changes in tissue and airway parameters is indicative of the marked growth occurring in the lung parenchyma during this developmental period.

Future methodological modifications will include circuit changes to facilitate accurate assessment of the extent to which lung volume is elevated above functional residual capacity during oscillatory measurements. This approach will facilitate measurement of the volume dependence of partitioned lung mechanics. As the airways are likely to be splinted open when measurements performed at raised volume (31), changes in airway resistance with growth of the airways may be obscured. Ultimately, measurements obtained in the resting physiologic state at or around functional residual capacity would provide more relevant information to the understanding of functional consequences of disease in the clinical setting and may have particular relevance for understanding airway disease. The practicalities of such measurements will be targeted in future studies.

Clinical significance. We have shown that the LFOT can be obtained during a relatively brief interruption to the normal breathing pattern during spontaneous quiet sleep, even in rapidly breathing preterm infants. Like any measurement in an unsedated infant population, these measurements took time and patience. Although the median duration of the LFOT studies was relatively lengthy, this was due at least in part to the preliminary nature of our investigations. When performing a routine study, it was possible to complete up to eight complete measurements in less than 10 min, once the infant was in a deep quiet sleep. A formal feasibility study will be required before the LFOT can be recommended for more widespread use.

The successful application of a technique that partitions measurements of lung mechanics into airway and tissue compartments is of particular interest for the preterm infant, in whom parenchymal disease forms the major component of acute respiratory illness, and failure of alveolarization has been targeted as a major feature of subsequent chronic lung disease $(1,2)$. Associations between various FOT parameters (resistance, reactance, frequency dependence, and resonance frequency) and clinical history or the presence/absence of chronic lung disease have been shown using FOT techniques employing higher frequency ranges than those used with the LFOT approach $(32,33)$. Further studies are necessary to determine whether the low-frequency airway and tissue mechanical parameters derived from LFOT provide some additional advantage to routine FOT for assessment of the presence and severity of lung disease in the preterm infant. Likewise, it would be useful to combine the LFOT with data obtained from multiple breath washout to detect to establish how changes in ventilation inhomogeneities associated with maturation influence the developmental changes in properties of the tissues elicited from impedance data using the constant phase model. Other potential applications for the LFOT include ascertaining the mechanically optimal lung inflation in the intubated infant during high-frequency oscillatory ventilation (22). Given that 
frequency dependence is incorporated into the LFOT parameters, there is a further possibility for this technique to be used as an objective outcome measure for clinical trials evaluating differences between different ventilatory modalities and strategies.

\section{CONCLUSIONS}

These studies represent an important step forward in the development of LFOT as a clinical tool. We showed that technically acceptable measurements of partitioned lung mechanics are achievable at the cotside of the unsedated sleeping newborn infant using low-frequency forced oscillations. The studies have highlighted the dominant changes in the viscous and to a lesser extent also the elastic properties of the tissues during early postnatal life in the moderately immature lung, reinforcing earlier observations in preterm lambs (20-22). Formal feasibility and reproducibility studies are needed to establish the practicalities of including this technique as a routine neonatal lung function test.

Acknowledgments. The authors thank the babies and their parents who participated in this study. We also thank Dr. Jane Hawdon and the staff of Neonatal Unit at University College London Hospital for their support and assistance in making these measurements possible, and Ms. Anne Cantarella, who provided especially valuable help in subject recruitment and assistance in obtaining the measurements.

\section{REFERENCES}

1. Coalson JJ, Winter VT, Siler-Khodr T, Yoder BA 1999 Neonatal chronic lung disease in extremely immature baboons. Am J Respir Crit Care Med 160:1333-1346

2. Coalson JJ 2003 Pathology of new bronchopulmonary dysplasia. Semin Neonatol 8:73-81

3. Parker TA, Abman SH 2003 The pulmonary circulation in bronchopulmonary dysplasia. Semin Neonatol 8:51-61

4. Stocks J, Sly PD, Tepper RS, Morgan WJ 1996 Infant Respiratory Function Testing. Wiley-Liss, New York, pp 1-577

5. Stocks J 2004 Infant respiratory function testing: is it worth all the effort? Paediatr Anaesth 14:537-540

6. Folke M, Cernerud L, Ekstrom M, Hok B 2003 Critical review of non-invasive respiratory monitoring in medical care. Med Biol Eng Comput 41:377-383

7. DuBois AB, Brody AW, Lewis DH, Burgess BF Jr 1956 Oscillation mechanics of lungs and chest in man. J Appl Physiol 8:587-594

8. Oostveen E, MacLeod D, Lorino H, Farre R, Hantos Z, Desager K, Marchal F; ERS Task Force on Respiratory Impedance Measurements 2003 The forced oscillation technique in clinical practice: methodology, recommendations and future developments. Eur Respir J 22:1026-1041
9. Hantos Z, Daroczy B, Suki B, Nagy S, Fredberg JJ 1992 Input impedance and peripheral inhomogeneity of dog lungs. J Appl Physiol 72:168-178

10. Hantos Z, Daroczy B, Suki B, Galgoczy G, Csendes T 1986 Forced oscillatory impedance of the respiratory system at low frequencies. J Appl Physiol 60:123-132

11. Sly PD, Hayden MJ, Petak F, Hantos Z 1996 Measurement of low-frequency respiratory impedance in infants. Am J Respir Crit Care Med 154:161-166

12. Hall GL, Hantos Z, Wildhaber JH, Petak F, Sly PD 2001 Methacholine responsiveness in infants assessed with low frequency forced oscillation and forced expiration techniques. Thorax 56:42-47

13. Hall GL, Hantos Z, Wildhaber JH, Sly PD 2002 Contribution of nasal pathways to low frequency respiratory impedance in infants. Thorax 57:396-399

14. Hall GL, Hantos Z, Petak F, Wildhaber JH, Tiller K, Burton PR, Sly PD 2000 Airway and respiratory tissue mechanics in normal infants. Am J Respir Crit Care Med 162:1397-1402

15. Hall GL, Hantos Z, Sly PD 2001 Altered respiratory tissue mechanics in asymptomatic wheezy infants. Am J Respir Crit Care Med 164:1387-1391

16. Petak F, Hayden MJ, Hantos Z, Sly PD 1997 Volume dependence of respiratory impedance in infants. Am J Respir Crit Care Med 156:1172-1177

17. Hayden MJ, Petak F, Hantos Z, Hall G, Sly PD 1998 Using low-frequency oscillation to detect bronchodilator responsiveness in infants. Am J Respir Crit Care Med 157:574-579

18. Gaultier C, Fletcher M, Beardsmore C, Motoyama E, Stocks J 1996 Measurement conditions. In Stocks J, Sly PD, Tepper RS, Morgan WJ (eds) Infant Respiratory Function Testing. Wiley-Liss, New York, pp 29-44.

19. Fredberg JJ, Stamenovic D 1989 On the imperfect elasticity of lung tissue. J App Physiol 67:2408-2419

20. Pillow JJ, Jobe AH, Collins RA, Hantos Z, Ikegami M, Moss TJ, Newnham JP, Willet KE, Sly PD 2004 Variability in preterm lamb lung mechanics after intra-amniotic endotoxin is associated with changes in surfactant pool size and morphometry. Am J Physiol Lung Cell Mol Physiol 287:L992-L998

21. Pillow JJ, Hall GL, Willet KE, Jobe AH, Hantos Z, Sly PD 2001 Effects of gestation and antenatal steroid on airway and tissue mechanics in newborn lambs. Am J Respir Crit Care Med 163:1158-1163

22. Pillow JJ, Sly PD, Hantos Z 2004 Monitoring of lung volume recruitment and derecruitment using oscillatory mechanics during high-frequency oscillatory ventilation in the preterm lamb. Pediatr Crit Care Med 5:172-180

23. Stocks J, Dezateux C, Hoo AF, Rabbette PS, Costeloe K, Wade A 1996 Delayed maturation of Hering-Breuer inflation reflex activity in preterm infants. Am J Respir Crit Care Med 154:1411-1417

24. Davenport PW, Dalziel DJ 1989 High-frequency ventilation-induced apnea: interaction of frequency, volume, FRC, and CO2. J Appl Physiol 66:2462-2467

25. Kohl J, Freund U, Koller EA 1991 Reflex apnea induced by high-frequency oscillatory ventilation in rabbits. Respir Physiol 84:209-222

26. Hantos Z, Adamicza A, Govaerts E, Daroczy B, 1992 Mechanical impedances of lungs and chest wall in the cat. J Appl Physiol 73:427-433

27. Desager KN, Cauberghs M, Naudts J, van de Woestijne KP 1999 Influence of upper airway shunt on total respiratory impedance in infants. J Appl Physiol 87:902-909

28. DorkinHL,StarkAR,WerthammerJW, StriederDJ,FredbergJJ,FrantzID 3rd 1983 Respiratory system impedance from 4 to $40 \mathrm{~Hz}$ in paralyzed intubated infants with respiratory disease. J Clin Invest 72:903-910

29. Sly PD, Collins RA, Thamrin C, Turner DJ, Hantos Z 2003 Volume dependence of airway and tissue impedances in mice. J Appl Physiol 94:1460-1466

30. Yuan H, Cavalcante FS,LutchenKR,IngenitoEP, SukiB 2000 Effects of collagenase and elastase on the mechanical properties of lung tissue strips. J Appl Physiol 89:3-14

31. Lai-Fook SJ, Hyatt RE, Rodarte JR 1978 Effect of parenchymal shear modulus and lung volume on bronchial pressure-diameter behavior. J Appl Physiol 44:859-868

32. Malmberg LP, Mieskonen S, Pelkonen A, Kari A, Sovijarvi AR, Turpeinen M 2000 Lung function measured by the oscillometric method in prematurely born children with chronic lung disease. Eur Respir J 16:598-603

33. Duiverman EJ, Den Boer JA, Roorda RJ, Rooyackers CM, Valstar M, Kerrebijn KF 1988 Lung function and bronchial responsiveness measured by forced oscillometry after bronchopulmonary dysplasia. Arch Dis Child 63:727-732 